\title{
Utilização de farinha de silagem de pescado em dietas para o jundiá na fase juvenil
}

\author{
Use of fish silage flour in diets for the jundiá in the juvenile phase
}

\begin{abstract}
Dariane Beatriz Schoffen Enke ${ }^{\mathrm{I}^{*}}$ Paulo Soares Lopes ${ }^{\mathrm{I}}$ Henrique Augusto Kich ${ }^{\mathrm{II}}$ Aline Paff Britto ${ }^{\mathrm{III}}$ Marcela Soquetta ${ }^{\mathrm{IV}}$ Juvêncio Luís Osório Fernandes Pouey $^{\mathrm{V}}$
\end{abstract}

\section{RESUMO}

Neste trabalho, foram avaliados o desempenho e o rendimento de carcaça em juvenis de jundiá Rhamdia quelen, alimentados com farinha de silagem química de rejeitos de pescado em substituição à levedura de cana, em dietas à base de ingredientes vegetais (dieta controle). Os 135 animais (peso médio inicial de 48,11 $\pm 5,54 \mathrm{~g}$ ) foram distribuídos em cinco tratamentos com três repetições ao acaso. Cada unidade de observação foi composta por um tanque circular (1000 litros) abastecido com 200 litros de água, com temperatura controlada, em um sistema fechado de criação contendo nove animais cada. Os peixes foram alimentados durante 75 dias, duas vezes ao dia, na proporção de $10 \%$ da biomassa total. Foram testadas dietas contendo: 0, 12,5, 25, 37,5 e 50\% de farinha de silagem. Os resultados indicaram um efeito quadrático $(P<0,05)$ da inclusão de farinha de silagem de pescado sobre o peso final, o ganho em peso, o comprimento total e a taxa de crescimento específico. A inclusão de 3033\%- da farinha de silagem química de rejeitos de pescado na dieta proporcionou melhor desempenho para juvenis de jundiá, não afetando a sobrevivência e a qualidade de água.

Palavras-chave: crescimento, Rhamdia quelen, rejeitos da pesca, silagem.

\section{ABSTRACT}

This study evaluated the productive performance and carcass yield of jundiá (Rhamdia quelen) fed with different fish dregs chemical silage flour concentrations in substitution to the sugar cane yeast in a diet based on vegetable ingredients (control diet). Animals with initial weight of $48.11 \pm 5.54 \mathrm{~g}$ were distributed in 5 treatments with 3 replicates, in a completely randomized design. Each observation unit consisted of a 1,000 liter polipropilene tank, with 200 liters of water, with 9 animals, in a thermo-regulated system with water recirculation. During 75 days, twice daily ( $9 \mathrm{~h}$ and $17 \mathrm{~h}$ ) the following diets were offered, in the proportion of 7\% total biomass: 0\% (control), $12.5 \%, 25 \%, 37.5 \%$ and $50 \%$ of silage flour. Results showed a quadratic effect $(P<0.05)$ for inclusion levels of fish silage flour on final weight, weight gain, total length and specific growth rate. The inclusion of $30-35 \%$ of fish dregs chemical silage flour in the diet, results in better production performance of jundiá juveniles without affecting the survival and the water quality.

Key words: growth, Rhamdia quelen, fish dregs, silage.

\section{INTRODUÇÃO}

O farelo de soja é a fonte protéica de origem vegetal mais utilizada em dietas para peixes, pela sua disponibilidade e pelo seu valor nutritivo. Pelo seu custo elevado, fontes protéicas alternativas que possam substituí-lo têm sido pesquisadas (SOARES et al., 2001). A levedura de cana (Saccharomyce cerevisiae) é um ingrediente com bom teor protéico, variando de 37 até $45 \%$ de proteína bruta, sendo muito utilizada em rações para diversas espécies de peixes. Para o jundiá, alguns trabalhos mostram excelente

IPrograma de Pós-graduação em Zootecnia, Faculdade de Agronomia Eliseu Maciel (FAEM), Universidade Federal de Pelotas (UFPel), Pelotas, RS, Brasil. E-mail: schoffenke@yahoo.com.br. *Autor para correspondência.

IICurso de Agronomia, UFPel, Pelotas, RS, Brasil.

"IICurso de Química de Medicina Veterinária, UFPel, Pelotas, RS, Brasil.

${ }^{\text {IV }}$ Curso de Química de Alimentos, UFPel, Pelotas, RS, Brasil.

${ }^{v}$ Departamento de Zootecnia, FAEM, UFPel, Pelotas, RS, Brasil. 
resposta em ganho de peso para larvas e juvenis, em que a levedura foi um dos constituintes da base protéica (PIAIA \& RADÜNZ NETO, 1997; COLDEBELLA \& RADÜNZ NETO, 2002).

Dentre os alimentos de origem animal, a farinha de peixe é a mais empregada na aqüicultura, sendo uma excelente fonte de energia digestível e uma boa fonte de minerais essenciais e vitaminas essenciais (TACON, 1996). Pelo fato de apresentar elevado valor biológico e equilíbrio em aminoácidos essenciais, a farinha de peixe é considerada um alimento padrão para ensaios experimentais, sendo a fonte de proteína preferida em dietas para peixes; porém, é igualmente considerada um dos ingredientes mais caros em dietas para esses animais (TACON, 1996; PEZZATO, 1995). Dessa forma, se faz necessário o estudo de fontes alternativas de proteína a fim de baratear as dietas e, por conseqüência, reduzir os custos de produção (PADUA et al., 2000). Tendo em vista a importância da utilização de fontes alternativas de proteínas na alimentação animal, a farinha de silagem química de rejeitos da pesca surge como uma fonte, por exemplo, de substituição à levedura de cana em dietas de peixes.

O objetivo deste trabalho foi avaliar o desempenho e o rendimento de carcaça em juvenis de jundiá (Rhamdia quelen) alimentados com diferentes concentrações de farinha de silagem química de rejeitos da pesca em substituição à levedura de cana da ração controle.

\section{MATERIAL E MÉTODOS}

O experimento foi conduzido no Laboratório de Ictiologia, do Departamento de Zootecnia, da Universidade Federal de Pelotas (UFPel). Os rejeitos do birú (Cyphocharax voga) foram passados em moedor de carne elétrico e colocados em baldes plásticos. Posteriormente, foram realizadas a homogeneização e incorporação de $10 \%$ de ácido acético (SEIBEL \& SOUZA-SOARES, 2003).

Utilizou-se uma combinação protéica de levedura de cana e farelo de soja, com 33\% de PB, na qual foram substituídos os níveis da levedura de cana em $25,50,75$ e $100 \%$ por farinha de silagem de rejeito de pescado, que equivalem a $0,12,5,25,37,5$ e $50 \%$ de farinha de silagem na dieta. Utilizou-se para o cálculo das dietas o Super Crac 4,0 (TD Software). Os ingredientes foram homogeneizados em misturador tipo "Y”, peletizados em "moedor de carne" e secos a $50^{\circ} \mathrm{C}$, durante 24 horas, em estufa com circulação de ar. As dietas foram trituradas em moinho e peneiradas para obtenção de partículas com diâmetro entre 1 e 2mm, sendo embaladas em pequenas porções e armazenadas sob refrigeração $\left(4^{\circ} \mathrm{C}\right)$. As dietas foram analisadas para verificação da composição bromatológica (AOAC, 1995), como mostra a tabela 1.

Foram utilizados 135 juvenis de jundiá com peso médio de $48,11 \pm 5,54 \mathrm{~g}$. Os animais foram distribuídos em 15 tanques circulares com capacidade de 1000 litros, abastecidas com 200 litros de água numa vazão de 2,4 litros por minuto durante as 24 horas do dia, com entrada e saída de água individual e termoregulada, contendo nove animais por unidade experimental.

A salinidade da água foi aumentada com a adição de $2 \mathrm{~g}$ de sal grosso comum por litro de água durante os períodos de adaptação e experimental, para manutenção do equilíbrio osmótico dos animais. Diariamente, foram medidos os parâmetros físicoquímicos da água: temperatura, amônia total, nitrito, alcalinidade, $\mathrm{pH}$ e oxigênio dissolvido ( $\mathrm{mg} \mathrm{L}^{-1}$ ) (APHA, 1998). Para a medição da temperatura, utilizou-se um termômetro com bulbo de mercúrio; para o oxigênio, um oxímetro digital (modelo 55 da YSI); para pH, um potenciômetro (modelo AT 310), para as demais análises, um kit colorimétrico marca Alfa-Tecnoquímica. Aágua utilizada para a realização das análises foi coletada sempre antes da limpeza diária. Também foram realizadas limpezas dos encanamentos que compõem o sistema de cada unidade experimental.

Após o período de adaptação (15 dias), iniciou-se o período experimental. Durante 75 dias, os peixes foram alimentados duas vezes ao dia (9 e 17 horas), na proporção de $10 \%$ do peso vivo, corrigido quinzenalmente, e submetidos a uma biometria individual (após jejum de 24 horas), que consistia na pesagem (balança digital $0,1 \mathrm{~g}$ ) e na medição dos comprimentos padrão e total (régua milimetrada). Ao final do período experimental, todos os animais foram anestesiados e sacrificados para determinação do rendimento de carcaça (peixe eviscerado e com cabeça).

Avaliou-se a influência da silagem de pescado nos seguintes parâmetros: peso final obtido, comprimento total e sobrevivência (S): quantidade de peixes sobreviventes em relação ao número inicial de peixes em cada tratamento. A taxa de crescimento específico diário foi calculada de acordo com LEGENDRE e KERDCHUEN (1995) por meio da equação: TCE = 100 (ln Pm final $-\ln$ Pm inicial $)(t)-1$, em que $\ln$ = logaritmo neperiano; $\mathrm{Pm}=$ peso médio; e t=tempo em dias. Para o cálculo do Fator de Condição, utilizou-se a equação: $\mathrm{FC}=$ Peso/Comprimento total ${ }^{3} \mathrm{X}$ 100 e rendimento de carcaça determinado por meio da diferença entre o peso inteiro do peixe e seu peso eviscerado, com as brânquias e a cabeça (MELO et al., 2002). 
Tabela 1 - Composição das dietas experimentais utilizadas no experimento em \% da Matéria Seca (MS).

\begin{tabular}{|c|c|c|c|c|c|}
\hline \multirow{2}{*}{ Ingredientes (\%) } & \multicolumn{5}{|c|}{ 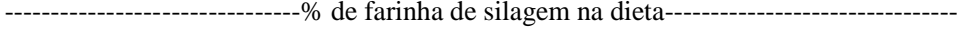 } \\
\hline & 0 & 12,5 & 25 & 37,5 & 50 \\
\hline Farelo de soja & 27,00 & 22,00 & 18,00 & 13,00 & 9,00 \\
\hline Levedura de cana & 50,00 & 37,50 & 25,00 & 12,50 & 0,00 \\
\hline Milho triturado & 11,00 & 14,00 & 18,00 & 22,00 & 24,00 \\
\hline Óleo de canola & 3,00 & 3,00 & 3,00 & 3,00 & 3,00 \\
\hline Farelo de trigo & 5,00 & 7,00 & 7,00 & 8,00 & 10,00 \\
\hline Farinha de silagem & 0,00 & 12,50 & 25,00 & 37,50 & 50,00 \\
\hline Premix $^{1}$ & 2,00 & 2,00 & 2,00 & 2,00 & 2,00 \\
\hline Sal $(\mathrm{NaCl})$ & 1,00 & 1,00 & 1,00 & 1,00 & 1,00 \\
\hline Fosfato bicálcico & 1,00 & 1,00 & 1,00 & 1,00 & 1,00 \\
\hline Total & 100,00 & 100,00 & 100,00 & 100,00 & 100,00 \\
\hline \multicolumn{6}{|l|}{ Composição bromatológica² (\%) } \\
\hline Matéria seca & 90,73 & 91,36 & 92,55 & 93,54 & 94,71 \\
\hline Extrato etéreo & 7,73 & 10,16 & 12,81 & 11,37 & 13,46 \\
\hline Cinzas & 6,65 & 8,85 & 11,21 & 13,36 & 15,27 \\
\hline Proteína bruta & 32,57 & 32,50 & 32,65 & 32,50 & 32,80 \\
\hline Fibra bruta & 2,56 & 2,57 & 2,45 & 2,37 & 2,39 \\
\hline Energia digestível (kcal/kg) & 3463,00 & 3444,00 & 3458,00 & 3457,00 & 3434,00 \\
\hline Relação ED:PB & 106,32 & 105,97 & 105,91 & 106,37 & 104,69 \\
\hline
\end{tabular}

${ }^{1}$ Composição do premix: Vit. A: 2.500,0000UI g-1 ${ }^{-1}$ Vit. $\mathrm{D}_{3}$ : 500,0000UI g ${ }^{-1}$; Vit. E: 20.000,0000mg kg ${ }^{-1}$; Vit. C: 25.000,0000mg kg-1; Vit. K3: 350.000,0000 $\mathrm{mg} \mathrm{kg}^{-1}$; Riboflavina: 8.250,0000 $\mathrm{mg} \mathrm{kg}^{-1}$; Ácido Pantotênico: 20.000,0000mg kg-1; Biotina: 50.000,0000mcg kg-1; ácido Nicotínico: 37.500,0000mg kg-1; Vit. $\mathrm{B}_{12}$ : 10.000,0000mcg kg-1; Ácido Fólico: 1.500.000,0000mg kg-1 Tiamina: 7.000,0000mg kg-1; Piridoxina: 7.250,0000mg kg-1; Cu: 3.000,0000mg kg-1; Fe: 25.000,000mg kg-1; Mn: 15.000,0000mg kg-1; 1 : 660,0001mg kg ; Se: 110,0000mg kg-1 Zn: 30.000,0000mg kg ${ }^{-1}$; Co: 250,0000mg kg-1 Colina 165.000,0000mg kg-1;

${ }^{2}$ Análises bromatológicas realizadas no Laboratório de Nutrição Animal, do Departamento de Zootecnia, da Faculdade de Agronomia Eliseu Maciel, da Universidade Federal de Pelotas - UFPel, Pelotas - RS.

O delineamento experimental foi o inteiramente casualizado, com cinco tratamentos e três repetições. Os dados obtidos foram submetidos à análise de variância (ANOVA) e regressão polinomial, sendo utilizando o programa Statistica ${ }^{\circledR} 5.0$ (STATSOFT, INC. 1998).

\section{RESULTADOS E DISCUSSÃO}

Os parâmetros de qualidade de água do sistema experimental estiveram dentro dos limites considerados satisfatórios para a criação da espécie (CARDOZO, 2000 e PIEDRAS et al., 2004). As médias observadas foram: temperatura $\left(23,0 \pm 2,2^{\circ} \mathrm{C}\right)$, amônia total $\left(0,5 \pm 0,3 \mathrm{mg} \mathrm{L}^{-1}\right)$, nitrito $\left(0,07 \pm 0,01 \mathrm{mg} \mathrm{L}^{-1}\right)$, alcalinidade $\left(47,8 \pm 13,4 \mathrm{mg} \mathrm{CaCO}_{3} \mathrm{~L}^{-1}\right), \mathrm{pH}(7,5 \pm 0,2) \mathrm{e}$ oxigênio dissolvido $\left(5,4 \pm 0,6 \mathrm{mg} \mathrm{L}^{-1}\right)$.

Na tabela 2 podem ser encontrados os valores médios de desempenho produtivo e rendimento de carcaça dos juvenis de jundiá, alimentados com e sem farinha de silagem na dieta. Os pesos no final do experimento (75 dias) apresentaram diferença significativa entre os tratamentos com um efeito quadrático $(\mathrm{P}<0,05)$, representado pela equação $y=-0,0294 x^{2}+1,8983 x+63,035$, sendo que derivando a equação obtém-se um ponto de máximo igual a 30,61\%, indicando que os melhores pesos finais estão entre os tratamentos de 25 a 37,5\% de substituição de farinha de silagem.

OLIVEIRA (2003), com valores inferiores de silagem, não encontrou diferença significativa entre as médias de peso final dos black bass (Micropterus salmoides), alimentados com dietas contendo diferentes níveis de inclusão (1, 2, 3, 4, 5 e 6\%) de silagem de peixe (inteiro) como atrativo. Para juvenis de piauçu (Leporinus macrocephalus), alimentados com dietas contendo $(0,2,4,6$ e $8 \%$ ) de silagem de resíduos de filetagem de tilápias por 84 dias, BUENO (2006) não observou diferença significativa no peso dos animais. Nesse experimento, os níveis de inclusão de silagem foram maiores ( 0 a $50 \%$ ), o suficiente para apresentar algum resultado com diferenças significativas entre os tratamentos.

Os resultados obtidos mostraram que as médias de ganho de peso foram maiores nos tratamentos com inclusão de farinha de silagem, 
Tabela 2 - Desempenho produtivo e rendimento de carcaça de juvenis de jundiá (Rhamdia quelen) alimentados com níveis crescentes de farinha de silagem na dieta durante 75 dias.

\begin{tabular}{|c|c|c|c|c|c|c|}
\hline \multirow{3}{*}{ Variáveis } & \multicolumn{5}{|c|}{ 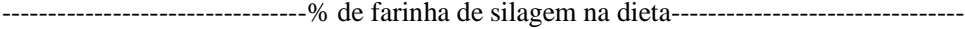 } & \multirow{3}{*}{$\mathrm{p}$} \\
\hline & & & & & & \\
\hline & 0 & 12,5 & 25 & 37,5 & 50 & \\
\hline PI (g) & 48,97 & 47,69 & 48,79 & 47,58 & 47,51 & - \\
\hline $\mathrm{PF}^{1}$ (g) & 64,40 & $77,77^{\mathrm{c}}$ & 97,12 & 90,63 & 84,78 & $3,9 E-8$ \\
\hline $\mathrm{GP}^{2}(\mathrm{~g})$ & 15,43 & 30,07 & 48,33 & 42,83 & 37,26 & $1,0 \mathrm{E}-5$ \\
\hline CTi (cm) & 17,79 & 17,70 & 18,02 & 17,98 & 17,78 & - \\
\hline $\mathrm{CTf}^{3}(\mathrm{~cm})$ & 19,58 & 20,49 & 22,27 & 21,32 & 21,06 & $1,6 \mathrm{E}-8$ \\
\hline $\mathrm{TCE}^{4}(\%)$ & 0,36 & 0,65 & 0,92 & 0,85 & 0,77 & $3,8 \mathrm{E}-6$ \\
\hline FC & 0,86 & 0,90 & 0,88 & 0,93 & 0,91 & 0,2143 \\
\hline SOB (\%) & 100 & 100 & 100 & 100 & 100 & - \\
\hline RC (\%) & 88,17 & 87,39 & 87,82 & 87,54 & 87,03 & 0,5625 \\
\hline
\end{tabular}

Peso Inicial (PI), peso final (PF), ganho peso (GP), comprimento total inicial (CTi), comprimento total final (CTf), taxa de crescimento específico (TCE), fator de condição (FC), sobrevivência (SOB), e rendimento de carcaça (RC).

${ }^{1}$ Efeito quadrático $(\mathrm{P}<0,05) \mathrm{y}=-0,0294 \mathrm{x}^{2}+1,8983 \mathrm{x}+63,035, \mathrm{R}^{2}=0,9189$

${ }^{2}$ Efeito quadrático $(\mathrm{P}<0,05) \mathrm{y}=-0,0293 \mathrm{x}^{2}+1,9186 \mathrm{x}+14,328, \mathrm{R}^{2}=0,9154$

${ }^{3}$ Efeito quadrático $(\mathrm{P}<0,05) \mathrm{y}=-0,0023 \mathrm{x}^{2}+0,1465 \mathrm{x}+19,462, \mathrm{R}^{2}=0,6324$

${ }^{4}$ Efeito quadrático $(\mathrm{P}<0,05) \mathrm{y}=-0,0005 \mathrm{x}^{2}+0,0327 \mathrm{x}+0,3543, \mathrm{R}^{2}=0,8738$

$\mathrm{P}=$ nível de significância.

indicando que as diferentes percentagens de silagem na dieta possivelmente influenciaram a palatabilidade, atratividade e digestibilidade das rações fornecidas aos juvenis de jundiá. SOUZA et al. (2007) também concluíram que a adição de $30 \%$ de silagem biológica de resíduos de pescado favoreceu o ganho de peso de tilápias (peso inicial de 15,32) após 97 dias experimentais.

Quando submetidos à análise de regressão polinomial, o ganho de peso médio e a taxa de crescimento específico demonstraram efeito quadrático $(\mathrm{P}<0,05)$, sendo apresentado nas figuras 1 e 2 , respectivamente. Com a derivação das equações do ganho de peso médio e da taxa de crescimento específico $y=-0,0293 x^{2}+1,9186 x+14,328$ e $y=-0,0005 x^{2}$ $+0,0327 x+0,3543$, verifica-se que $32,7 \%$ de substituição de farinha de silagem de pescado oferecem o maior ganho de peso (46g) e a taxa de crescimento específico $(0,89)$ aos juvenis de jundiá.

As taxas de crescimento específico (TCE) obtidas neste trabalho foram inferiores às taxas obtidas por COLDEBELLA \& RADÜNZ NETO (2002), que obtiveram taxa de 4,93 com alevinos, LAZZARI et al. (2006), os quais encontraram valores acima de três, trabalhando com dietas à base de farinha de carne e farelo de soja na alimentação de juvenis de jundiá durante 90 dias experimentais, e MEYER \& FRACALOSSI (2004), que também obtiveram TCE de 1,8 a 2,60 com alevinos dessa espécie. O peso médio inicial dos peixes desses estudos relatados foi de $1,18 \mathrm{~g}$, 15,0 e 1,52g, respectivamente, bem menores do que os peixes do presente experimento, que tinham maior tamanho e peso médio inicial de 48,11 $\pm 5,54$ g e que apresentaram menor TCE $(<1)$. Possivelmente tais diferenças se devem a fatores como a composição das dietas e principalmente a relação inversamente proporcional existente entre o peso corporal e a taxa de crescimento específico (KAUSHIK, 1998).

LOSEKANN et al. (2008), trabalhando com juvenis de jundiá de $71 \mathrm{~g}$ e utilizando farinha de carne e ossos e farelo de soja como fontes protéicas, testaram diferentes fontes de óleo nas dietas com 33\% de proteína bruta e $3200 \mathrm{kcal} \mathrm{kg}^{-1}$ de energia digestível. Nesse estudo, os autores obtiveram um aumento de 50 a $60 \mathrm{~g}$ de peso com 60 dias de experimento e taxa de crescimento específica de 0,70 a 0,76. SOUZA et al. (2007), trabalhando com jundiás com peso médio inicial de 80,4g avaliados durante 135 dias, obtiveram peso médio final de 189,5g com TCE de 0,63. Esses resultados comparados evidenciam que, nessa faixa de peso, o jundiá apresentou um razoável potencial de crescimento.

VIDOTTI et al. (2002), trabalhando com silagem de peixe fermentada e ácida de diferentes matérias-primas em dietas do pacu (Piaractus mesopotamicus), com peso médio inicial de 7,96g durante 90 dias, não encontraram diferenças significativas entre as médias de ganho de peso e a taxa de crescimento específico, indicando que a utilização de silagem ácida e fermentada co-secas com farelo de soja e quirera de arroz não interferiu no crescimento dos peixes. 


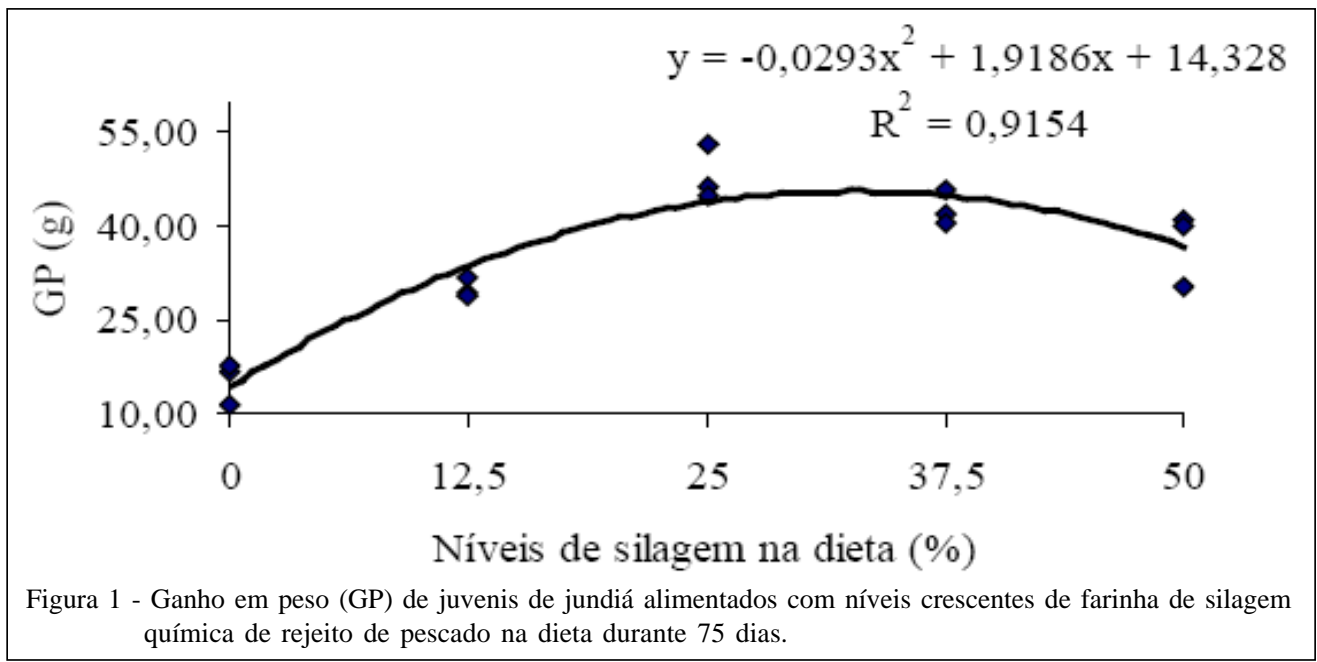

Na comparação com alevinos de tilápia do Nilo (Oreochromis niloticus) com peso médio inicial de $15,7 \mathrm{~g}$ durante 30 dias, alimentados com dietas contendo diferentes níveis de inclusão (0, 10, 20 e 30\%) de silagem de resíduos do filetagem de tilápia, CARVALHO et al. (2006) não encontraram diferença significativa $(\mathrm{P}>0,01)$ entre as médias de ganho de peso, mas observaram uma tendência de maior ganho de peso dos peixes alimentados com os maiores níveis de silagem. Alimentando a mesma espécie com silagem fermentada de resíduos da indústria e farelo de soja, FAGBENRO et al. (1994) encontraram a taxa de crescimento específico entre 2,64 e 2,66\% dia-1 . Além disso, esses s autores trabalharam com bagre africano (Clarias gariepinus), também alimentado com silagem fermentada de resíduos da indústria e farelo de soja, e a taxa de crescimento específica foi de 2,58\% $\mathrm{dia}^{-1}$.
Para o fator de condição (FC), variável que demonstra a condição corporal do peixe, não houve diferenças significativas entre os níveis, sendo que os dados foram semelhantes aos encontrados por COLDEBELLA \& RADÜNZ NETO (2002), quando utilizaram farinha de peixe e levedura de cana na dieta de juvenis de jundiá (0,89 a 1,07).

Em comparação com a espécie piauçu (Leporinus macrocephalus), os valores do fator de condição encontrados neste trabalho foram maiores $(0,86$ a 0,93$)$ que os encontrados por BOSCOLO et al. (2005) e BUENO (2006), variando o fator de condição de 0,05 a 0,93 , trabalhando com diferentes níveis de inclusão (0 a 15\%) de silagem de resíduos de filetagem de tilápias com animais de 0,19 g durante 35 dias e animais com 2 a 3,5g durante 84 dias, respectivamente.

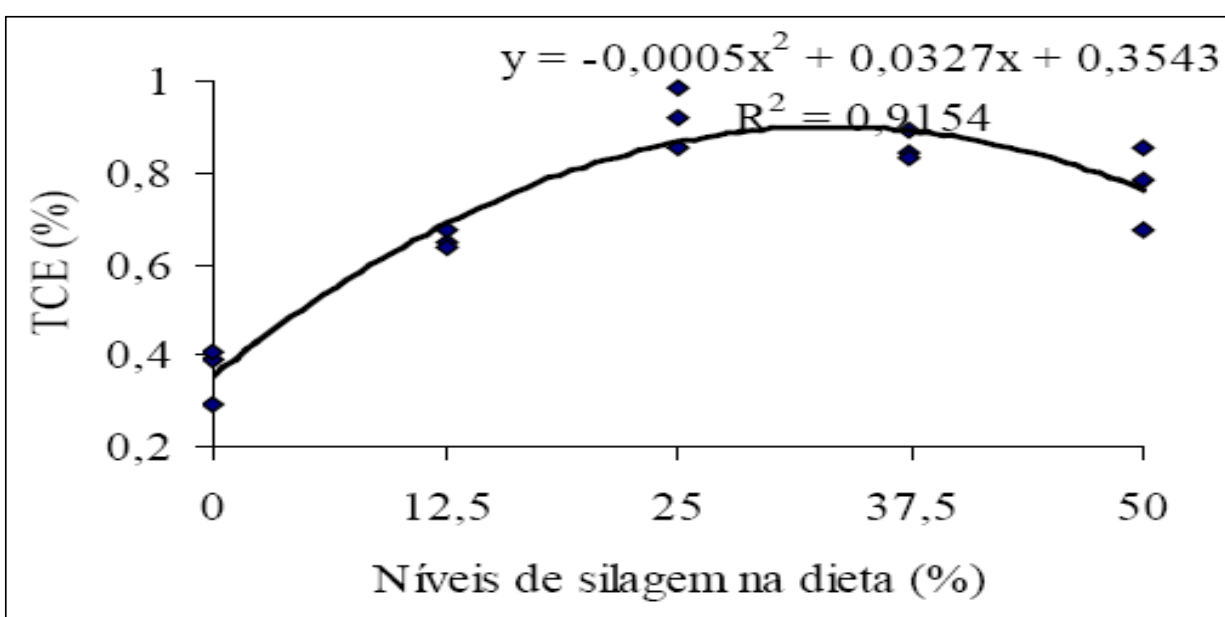

Figura 2 - Taxa de crescimento específico (TCE) de juvenis de jundiá alimentados com níveis crescentes de farinha de silagem química de rejeito de pescado na dieta durante 75 dias.

Ciência Rural, v.39, n.3, mai-jun, 2009. 
Os resultados da sobrevivência dos animais foram de $100 \%$ em todos os tratamentos, indicando ausência de substâncias tóxicas e/ou prejudiciais aos peixes. BOSCOLO et al. (2005) não encontraram diferenças significativas para sobrevivência dos juvenis de piauçu alimentados com dieta contendo diferentes níveis de inclusão $(0,5,10,15 \%)$ de silagem de resíduos de filetagem de tilápias, variando de 96 a 100\%. Da mesma forma, CARVALHO et al. (2006), quando avaliaram a sobrevivência de juvenis de tilápia do Nilo alimentados com dietas contendo diferentes níveis de inclusão (0 a 30\%) de silagem de resíduos da filetagem de tilápia, não encontraram diferença significativa $(\mathrm{P}>0,01)$.

Os valores de rendimento de carcaça variaram entre 87,03 e $88,17 \%$ e não diferiram estatisticamente $(\mathrm{P}>0,05)$, sendo superiores aos encontrados em alguns trabalhos já realizados com o jundiá, com valores entre 80 e $87 \%$ de rendimento de carcaça (CARNEIRO et al., 2003; LOSEKANN et al, 2008; LAZZARI et al., 2006; POUEY et al. 1999). Os resultados de desempenho dos peixes e rendimento de carcaça demonstraram que a presença da farinha de silagem, combinada com levedura de cana e farelo de soja, mostrou efeito positivo no crescimento do jundiá.

\section{CONCLUSÃO}

A farinha de silagem química de rejeitos da pesca pode substituir em até 33\% a levedura de cana em dietas para juvenis de jundiá (Rhamdia quelen).

\section{AGRADECIMENTO}

À Coordenação de Aperfeiçoamento de Pessoal de Ensino Superior (CAPES), pela de bolsa de estudo ao primeiro autor, e ao Conselho Nacional de Desenvolvimento Científico e Tecnológico (CNPq). Aos estagiários e funcionários do Laboratório de Ictiologia da Universidade Federal de Pelotas, pelo auxílio na preparação das instalações experimentais.

\section{REFERÊNCIAS}

AOAC. (Association of Official Analytical Chemists). Official methods of analysis of AOAC. 16.ed. Arlington, Virginia, USA, 1995. V.I e II.

APHA. Standard methods for examination of water and wastewater. New York: American Public Health Association, 1998. 824p.

BOSCOLO, W.R. et al. Farinha de resíduos da filetagem de tilápia em rações para alevinos de piauçu (Leporinus macrocephalus). Revista Brasileira de Zootecnia, v.34, n.6, p.819-1827, 2005.

BUENO, J.R. Silagem ácida de resíduos da filetagem de tilápia em dietas de alevinos de piauçu Leporinus macrocephalus. 2006. 45f. Dissertação (Mestrado em Aqüicultura) - Curso de pós-graduação em Aqüicultura, Universidade Estadual Paulista.

CARDOZO, L.B. Estudo da biometria, composição corporal e composição da carcaça do jundiá (Rhamdia sp.). 2000. 65f. Dissertação (Mestrado em Zootecnia) Faculdade de Agronomia Eliseu Maciel, Universidade Federal de Pelotas.

CARNEIRO, P.C.F et al. Processamento: o jundiá como matéria-prima. Panorama da Aqüicultura, v.13, n.78, p.1721, 2003.

CARVALHO, G.G.P et al. Silagem de resíduo de peixes em dietas para alevinos de tilápia-do-Nilo Oreochromis niloticus. Revista Brasileira de Zootecnia, v.35, n.1, p.126-130, 2006. Disponível em: http://www.scielo.br/scielo.php?script=sci_arttext\&pid=S151635982006000100016\&lng=en\&nrm=iso\&tlng=pt. Doi: 10.1590/ S1516-35982006000100016.

COLDEBELLA, I.J.; RADUNZ NETO, J. Farelo de soja na alimentação de alevinos de jundiá, Rhamdia quelen. Ciência Rural, v.32, n.3, p.499-503, 2002. Disponível em: http:// www.scielo.br/scielo.php?script=sci_arttext \&pid=S010384782002000300021\&lng=en\&nrm=iso\&tlng=pt. Doi: 10.1590/ S0103-84782002000300021.

FAGBENRO, O. Nutritive value of diets containing dried lactic acid fermented fish silage and soybean meal for juvenile Oreochromis niloticus and Clarias gariepinus. Aquatic Living Resource, Paris, v.7, p.79-85, 1994. Disponível em: http://www.alr-journal.org/ index.php?option=article\&access=doi\&doi=10.1051/alr:1994010. Doi: 10.1051/alr:1994010.

KAUSHIK, S.J. Nutritional bioenergetics and estimation of waste production in nonsalmonids. Aquatic Living Resources, v.4, n.11, p.211-217, 1998.

LAZZARI, R. et al. Diferentes fontes protéicas para a alimentação do jundiá (Rhamdia quelen). Ciência Rural, v.36, n.1, p.240246, 2006. Disponível em: http://www.scielo.br/ scielo.php ?script =sci_arttext \& pid=S 0103 $84782006000100037 \& \operatorname{lng}=$ en\&nrm=iso\&tlng=pt. Doi: $10.1590 /$ S0103-84782006000100037.

LEGENDRE, M.; KERDCHUEN, N. Larval rearing of an African Catfish Heterobranchus longifilis Teleostei, Claridae): effect of dietary lipids on growth survival and fatty acid composition of fry. Aquatic Living Resources, v.8, p.355363, 1995.

LOSEKANN, M.E. et al. Alimentação do jundiá com dietas contendo óleos de arroz, canola ou soja. Ciência Rural, v.38, n.1, p.225-230, 2008. Disponível em: http://www.scielo.br/ scielo.php? script =sci_arttext \& pid=s 0103 $84782008000100036 \& \operatorname{lng}=$ t $\&$ nrm=iso\&tlng=pt. Doi: $10.1590 /$ S0103-84782006000100037.

LOVELL, R.T. Use of soybean products in diets for aquaculture species. Journal Aquatic Products, v.2, p.27-52, 1988.

MELO, J.F.B. et al. Desenvolvimento e composição corporal de alevinos de jundiá (Rhamdia quelen) alimentados com dietas contendo diferentes fontes de lipídios. Ciência Rural, v.32, n.2, p.323-327, 2002. 
MEYER, G.; FRACALOSSI, D.M. Protein requirement of jundiá fingerlings, Rhamdia quelen, at two dietary energy concentrations. Aquaculture, v.240, n.4, p.331-343, 2004. Disponível em: http://www.sciencedirect.com/ science?_ob=ArticleURL\&_udi=B6T4D-4C006YM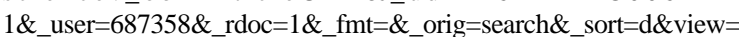 c \& a c ct $=$ C $000037899 \&$ version $=1 \&$ \& urlVersio $\mathrm{n}=0 \quad \& \quad \mathrm{u}$ s e $\mathrm{r}$ i $\mathrm{d}=\begin{array}{lllllllll}6 & 8 & 7 & 3 & 5 & 8 & \& & \mathrm{~m} & \mathrm{~d}\end{array}$ $=225$ c30fa487afe3f7f29a5e30c5fd647. Doi: 10.1016/ j.aquaculture.2004.01.034.

OLIVEIRA, A.M.B.S. Substituição de fontes protéicas de origem animal por fontes de origem vegetal em rações para Black Bass Micropterus salmoides. 2003. 103f. Tese (Doutorado em Agronomia) - Escola Superior de Agricultura Luiz de Queiroz, Piracicaba.

PADUA, D.M.C. et al. Morfometria de hepatócitos de pacu, Piaractus mesopotamicus, submetidos à dietas com níveis crescentes de levedura de álcool, Saccharomyces cerevisiae. A RS Veterinária, v.16, n.1, p.1-8, 2000

PIAIA, R.; RADÜNZ NETO, J. Avaliação de diferentes fontes protéicas sobre o desempenho inicial de larvas do jundiá $\boldsymbol{R} \boldsymbol{h a m d i a}$ quelen. Ciência Rural, v.27, n.2, p.319-323, 1997. Disponível em: http://www.scielo.br/scielo.php?script=sci_arttext\&pid=S010384781997000200025\&lng=en\&nrm=iso\&tlng=pt. Doi: 10.1590/ S0103-84781997000200025.

PIEDRAS, S.R.N. et al. Crescimento de juvenis de Jundiá (Rhamdia quelen), de acordo com a temperatura da água. Boletim do Instituto de Pesca, v.30, n.2, p.177-182, 2004

PEZZATO, L.E. Alimentos convencionais e não-convencionais disponíveis para indústria da nutrição de peixes no Brasil. In: SIMPÓSIO INTERNACIONAL SOBRE NUTRIÇÃO DE PEIXES E CRUSTRÁCEOS, 1995, Piracicaba. Anais...
Piracicaba: Escola superior de Agricultura “Luiz de Queiroz” Universidade de São Paulo (ESALQ), 1995. p.171.

POUEY, J.L.O. et al. Principais componentes corporais do jundiá Rhamdia $s p$ cultivado na densidade de um peixe $/ \mathrm{m}^{2}$ e dividido em quatro faixas de peso. In: REUNIÃO ANUAL DA SOCIEDADE. BRASILEIRA DE ZOOTECNIA, 36., 1999, Porto Alegre. Anais... São Paulo: Sociedade Brasileira de Zootecnia/Gmosis, [1999]. (CD-Rom).

SEIBEL,N.F.; SOUZA-SOARES, L.A. Produção de silagem química com resíduo de pescado marinho. Brazilian Journal of Food Technology, v.6, n.2, p.333-337, 2003.

SOARES C. M. et al. Substituição da proteína do farelo de soja pela proteína do farelo de canola em dietas para a tilápia do Nilo (Oreochromis niloticus) na fase de crescimento. Revista Brasileira de Zootecnia, v.30, n.4, p.1172-1177, 2001. Disponível em: http://www.scielo.br/scielo.php?script=sci_arttext\&pid=S151635982001000500006\&lng=en\&nrm=iso\&tlng=pt. Doi: 10.1590/ S1516-35982001000500006.

SOUZA, J.M.L. et al. Evolução do ganho de biomassa de alevinos de tilápia (Oreochromis niloticus) alimentados com silagem biológica de resíduos de pescado. Revista Brasileira de Nutrição Animal. v.1, n.1, p.17-25, 2007.

STATSOFT INC. Statistica for Windows (computer program manual). Tulsa, OK, USA, 1998. Total de p.?

TACON, A.G.J. Trends in Aquaculture production with particular reference to low income food deficit Countries 1984-1993. Food Aquaculture, v.12, p.6-9, 1996.

VIDOTTI, R.M. et al. Growt rate of pacu, Piaractus mesopotamicus, fingerlings fed diets containing co-dried fish silage as replacement of fish meal. Journal of Applied Aquaculture, v.12, n.4, p.77-88, 2002. 